\title{
Toward optimal end-of-life care for patients with advanced chronic obstructive pulmonary disease: Insights from a multicentre study
}

\author{
Graeme M Rocker MHSc DM FRCP FRCPC ${ }^{1}$, Peter M Dodek MD MSc FRCPC ${ }^{2}$, Daren K Heyland MD MSc FRCPC ${ }^{3}$;
} for the Canadian Researchers at the End of Life Network

GM Rocker, PM Dodek, DK Heyland; for the Canadian Researchers at the End of Life Network. Toward optimal endof-life care for patients with advanced chronic obstructive pulmonary disease: Insights from a multicentre study. Can Respir J 2008;15(5):249-254.

BACKGROUND: Understanding patients' needs and perspectives is fundamental to improving end-of-life (EOL) care. However, little is known of what quality care means to patients who have advanced lung disease.

OBJECTIVES: To describe ratings of importance and satisfaction with elements of EOL care, informational needs, decision-making preferences, obstacles to a preferred location of death, clinical outcomes, and health care use before and during an index hospital admission for patients who have advanced chronic obstructive pulmonary disease (COPD).

METHODS: A questionnaire with regard to quality EOL care was administered to patients older than 55 years of age who had advanced medical disease in five Canadian teaching hospitals.

RESULTS: For 118 hospitalized patients who had advanced COPD, the following items were rated as extremely important for EOL care: not being kept alive on life support when there is little hope for meaningful recovery (54.9\% of respondents), symptom relief $(46.6 \%)$, provision of care and health services after discharge $(40.0 \%)$, trust and confidence in physicians $(39.7 \%)$, and not being a burden on caregivers (39.6\%). Compared with patients who had metastatic cancer, patients with COPD had lower $(\mathrm{P}<0.05)$ satisfaction with care, interest in information about prognosis, cardiopulmonary resuscitation or mechanical ventilation, and referral rates to palliative care, whereas use of acute care services was higher $(\mathrm{P}<0.05)$ for patients who had advanced COPD.

CONCLUSION: Canadian patients who have advanced COPD identify several priorities for improving care. Avoidance of prolonged or unwanted life support requires more effective communication, decision making and goal setting. Patients also deserve better symptom control and postdischarge strategies to minimize perceived burdens on caregivers, emergency room visits and hospital admissions.

Key Words: Chronic obstructive pulmonary disease; Decision making; End-of-life care
Vers des soins de fin de vie optimaux chez les patients atteints d'une maladie pulmonaire obstructive chronique : Des aperçus d'une étude multicentrique

HISTORIQUE : Il est fondamental de comprendre les besoins et les points de vue du patient pour améliorer ses soins de fin de vie (FDV). Cependant, on ne sait pas grand-chose sur ce que signifie la qualité de vie pour les patients atteints d'une maladie pulmonaire avancée.

OBJECTIFS : Décrire les évaluations d'importance et de satisfaction envers les éléments des soins FDV, des besoins d'information, des préférences décisionnelles, des obstacles à l'égard du lieu souhaité pour mourir, des issues cliniques et de l'utilisation des soins de santé avant et pendant une hospitalisation de référence pour des patients atteints d'une maladie pulmonaire obstructive chronique (MPOC) avancée.

MÉTHODOLOGIE : Des patients de plus de 55 ans atteints d'une maladie avancée ont reçu un questionnaire au sujet de la qualité des soins FDV dans cinq hôpitaux universitaires canadiens.

RÉSULTATS : Pour 118 patients hospitalisés atteints d'une MPOC avancée, les éléments suivants étaient considérés d'une extrême importance en soins FDV : ne pas maintenir les fonctions vitales lorsqu'il y a peu d'espoir de rétablissement significatif (54,9\% des répondants), soulager les symptômes $(46,6 \%)$, dispenser des soins et des services de santé après le congé $(40,0 \%)$, avoir confiance au médecin $(39,7 \%)$ et ne pas être un fardeau pour les aidants $(39,6 \%)$. Par rapport aux patients atteints d'un cancer métastatique, les patients atteints d'une MPOC étaient $(\mathrm{P}<0,05)$ moins satisfaits des soins, moins intéressés à obtenir de l'information au sujet du pronostic, de la réanimation cardiopulmonaire ou de la ventilation mécanique et des taux d'aiguillage vers les soins palliatifs, tandis que les patients atteints d'une MPOC avancée utilisaient davantage les soins de courte durée $(\mathrm{P}<0,05)$.

CONCLUSION : Les patients canadiens atteints d'une MPOC avancée ont repéré plusieurs priorités pour améliorer les soins. Afin d'éviter le maintien prolongé ou non désiré des fonctions vitales, il faut des communications, des prises de décision et des fixations d'objectifs plus efficaces. Les patients méritent également un meilleur contrôle des symptômes et de meilleures stratégies avant leur congé afin de réduire au minimum le fardeau perçu sur les aidants, les consultations à l'urgence et les hospitalisations.
Chronic obstructive pulmonary disease (COPD) is the fourth leading cause of death in Canada. Because it is one of the most common chronic diseases, COPD is a major cause of morbidity and mortality. By 2018, it will cause more than
20,000 deaths in Canada per year and become the third leading cause of death in the world $(1,2)$. Of the six leading causes of death in the United States, COPD is the only one that has had a steadily increasing incidence over the past 30 years (3).

${ }^{1}$ Department of Medicine, Queen Elizabeth II Health Sciences Centre, Dalhousie University, Halifax, Nova Scotia; ${ }^{2}$ Department of Medicine, Center for Health Evaluation and Outcome Sciences, St Paul's Hospital, University of British Columbia, Vancouver, British Columbia;

${ }^{3}$ Department of Medicine, Kingston General Hospital, Queen's University, Kingston, Ontario

Correspondence: Dr Graeme M Rocker, Room 4457, Halifax Infirmary, 1796 Summer Street, Halifax, Nova Scotia B3H 3 A7.

Telephone 902-473-6611,fax 902-473-6202, e-mail gmrocker@dal.ca 
The final years before death for patients who have advanced COPD are characterized by progressive functional decline, poor quality of life and increasing dependency on informal caregivers. Patients who survive a hospitalization after an acute exacerbation of COPD (mortality of index admission is usually between $2.5 \%$ and $12 \%$ [4,5]) often experience shortness of breath for the rest of their lives (4). Relative to patients who have cancer, those who have COPD spend increasing lengths of time in the hospital because their disease progresses (6), have a higher burden of symptoms $(7,8)$, and are more likely to have poorly controlled (9) and incapacitating (10-14) dyspnea as the predominant symptom.

Understanding patients' needs and perspectives at the end of life (EOL) is fundamental to making improvements in provision of care. We have reported elsewhere the key elements of quality of EOL care identified by 434 seriously ill hospitalized patients at high risk of six-month mortality in Canada (15). We asked these patients (and their care-givers, if available) to identify aspects of EOL care most important to them, and we also asked patients and caregivers how satisfied they were with those aspects of care $(15,16)$. For seriously ill patients and their family members, the most important elements of quality EOL care were trust in the treating physician, avoidance of unnecessary life support, effective communication, continuity of care, and life completion. Variation in the perception of what matters the most indicated the need for customized or individualized approaches to providing EOL care $(15,16)$.

In the context of the need for better EOL care, and in response to recent calls for greater advocacy for patients who have $\operatorname{COPD}(17,18)$ and for involvement from palliative care providers in the management of advanced $\operatorname{COPD}(17,18)$, we have reviewed our COPD-specific data from the study described above $(15,16)$. For the 118 patients who had advanced COPD, we describe herein their ratings of importance and satisfaction with elements of EOL care, their informational needs and decision-making preferences, the obstacles (if any) to a preferred location of death, their clinical outcomes, and their health care use before and during an index hospital admission. To frame these findings, we draw comparisons with patients who had cancer from our previously published cohort. Illuminating these issues should enrich our nascent understanding of the needs and preferences of Canadian patients who have advanced COPD, and inform innovative approaches in Canada to improving care during the advanced stages of an incurable disease.

\section{METHODS}

A survey was conducted in five tertiary referral teaching hospitals in the cities of Vancouver (British Columbia), Halifax (Nova Scotia), Toronto (Ontario), Kingston (Ontario) and Edmonton (Alberta) between November 2001 and June 2003. The methodological details and aggregated study results have been published previously $(15,16)$. A total of 434 patients participated in the overall study. For the present substudy, 118 patients aged 55 years or older who were at high risk (30\% to $50 \%$ ) of COPD mortality at six months - as defined by at least two of the following: baseline arterial partial pressure of $\mathrm{CO}_{2}$ greater than $45 \mathrm{mmHg}$, documentation of a previous episode of acute respiratory failure within the past 12 months or of cor pulmonale, or forced expiratory volume in $1 \mathrm{~s}$ of $0.75 \mathrm{~L}$ or less - were included. (The definition of severe COPD was the same as that used in the Study to Understand Prognoses and
Preferences for Outcomes and Risks of Treatments [SUPPORT] study [4].) The present substudy also included the 166 patients who had cancer as defined by metastatic disease or grade 4 lymphoma. Patients who had probable communication difficulties, including those who did not understand English or who had cognitive barriers, were excluded. Before participation, all study subjects provided written informed consent. The study was approved by the institutional research ethics boards of the participating hospitals.

The processes for questionnaire development, patient screening, enrolment and the questions themselves were described previously $(15,16)$. Briefly, the questionnaire was composed of 28 items that addressed five domains: medical and nursing care, communication and decision making, social relationships and support, meaningful existence, and advance care planning. A research coordinator at each site administered the questionnaire in person to eligible patients. Response options were used to assess each item using a five-point ordinal scale for degree of importance (1, not at all important; 2, somewhat important; 3, important; 4, very important; and 5, extremely important) and satisfaction with care $(1$, not at all satisfied; 2 , not very satisfied; 3 , somewhat satisfied; 4 , very satisfied; and 5, completely satisfied). Patients were asked to indicate their preferences for decision making (leave decision up to doctor, doctor decides but considers my wishes, doctor and I share decision, I decide but consider the doctors' wishes, I make decision myself). Regarding informational needs for a particular intervention (eg, cardiopulmonary resuscitation [CPR]), patients were asked to indicate whether they would want a lot of information, some information or would not want any information.

Patients rated their preferences for current levels of care from 0 to 10 on a score card, in which 0 meant the focus of care was primarily concentrated on treatments to extend life as much as possible even if that meant having more pain and discomfort, to 10 , a plan of care that focuses only on relieving pain and discomfort as much as possible, even if that meant not living as long. From a chart review of responding patients, data concerning documentation of EOL discussions (whether EOL care orders were written [eg, CPR or the presence or absence of orders regarding level of care]), and health care use in the 12 months before the index admission (eg, emergency room visits, hospital admissions) and during the index admission (eg, intensive care unit [ICU] admission, ICU lengths of stay, intermediate care unit admission, palliative care referral and/or admission, and palliative care length of stay) were recorded. Finally, the six-month mortality rate was determined for enrolled patients by contact with patients, family members or family physicians.

\section{Statistical analysis}

Summary statistics for continuous and categorical data are provided. For comparisons between patients who had advanced COPD versus patients who had cancer, we used $t$ tests or Pearson's $\chi^{2}$ analysis when appropriate. In comparisons of patients' ratings of importance or satisfaction, the $\mathrm{P}$ value relates to the difference in proportions between patients who had COPD and patients who had cancer, rating an element as extremely important or completely satisfied in relation to the other categories of importance or satisfaction.

\section{RESULTS}

The mean $( \pm \mathrm{SD})$ age of the 118 patients who had COPD in the present study was $73 \pm 7.8$ years, and $34 \%$ lived alone. In 
TABLE 1

Demographics of study subjects

\begin{tabular}{|c|c|c|c|}
\hline Characteristic & COPD, n=118 & Cancer, n=166 & $\mathbf{P}$ \\
\hline Age, years, mean \pm SD & $73.27 \pm 7.84$ & $70.25 \pm 8.57$ & $<0.01$ \\
\hline Sex, \% & & & 0.94 \\
\hline Female & 52.5 & 45.8 & \\
\hline Male & 45.8 & 52.4 & \\
\hline Missing & 1.7 & 1.8 & \\
\hline Race, \% & & & 0.13 \\
\hline Caucasian & 98.3 & 91.0 & \\
\hline Other & 1.7 & 9.0 & \\
\hline Marital status, \% & & & 0.03 \\
\hline Married or common law & 47.5 & 57.2 & \\
\hline Widowed & 36.4 & 21.1 & \\
\hline Separated or divorced & 9.3 & 15.1 & \\
\hline Never married & 2.5 & 2.4 & \\
\hline Unknown & 4.2 & 4.2 & \\
\hline Living arrangements, $\%$ & & & 0.14 \\
\hline With spouse or partner & 45.8 & 57.2 & \\
\hline Alone & 33.9 & 28.9 & \\
\hline With other family & 16.1 & 8.4 & \\
\hline Nursing home & 1.7 & 0.6 & \\
\hline Chronic care facility & 0.8 & 1.8 & \\
\hline Unknown & 1.7 & 3.0 & \\
\hline Location of home, \% & & & 0.16 \\
\hline Rural & 21.4 & 28.8 & \\
\hline Urban & 78.6 & 71.6 & \\
\hline Overall quality of life, \% & & & 0.05 \\
\hline Excellent & 1.7 & 4.2 & \\
\hline Very good & 4.2 & 12.7 & \\
\hline Good & 16.9 & 15.7 & \\
\hline Fair & 39.8 & 27.7 & \\
\hline Poor & 33.1 & 30.7 & \\
\hline Unknown & 4.2 & 9.0 & \\
\hline
\end{tabular}

COPD Chronic obstructive pulmonary disease

addition, these patients were more likely to be older as well as widowed (Table 1), and less likely to have completed postsecondary education (data not shown). Compared with cancer patients, patients who had COPD reported an overall lower quality of life. Additional demographic characteristics are presented in Table 1.

The elements of EOL care that were most important to patients who had COPD were the following: 'not to be kept alive on life support when there is little hope for a meaningful recovery' (the only item rated extremely important by more than $50 \%$ of patients in both groups); 'to have relief of symptoms, ie, pain, shortness of breath, nausea, etc'; and 'to have an adequate plan of care and health services available to look after you at home upon discharge from hospital'. These three elements did not differ in importance from the ratings by patients who had cancer (Table 2), although two of the ten most important factors for patients who had COPD were significantly more important for cancer patients than COPD patients: 'trust and confidence in the doctors looking after you' (65.2\% versus $39.7 \%$, respectively) and 'complete things and prepare for life's end' ( $52.8 \%$ versus $30.7 \%$, respectively).
TABLE 2

Top 10 elements of end-of-life (EOL) care that patients with advanced chronic obstructive pulmonary disease (COPD) considered extremely important

\begin{tabular}{|c|c|c|c|c|}
\hline \multirow[b]{2}{*}{ Element } & \multirow{2}{*}{$\begin{array}{l}\text { OPD ( }(n=118), \\
n(\%)\end{array}$} & \multicolumn{2}{|c|}{ Cancer $(n=166)$} & \multirow[b]{2}{*}{$\mathbf{P}$} \\
\hline & & n (\%) & Rank & \\
\hline $\begin{array}{l}\text { 1. Not to be kept alive on life } \\
\text { support when there is little } \\
\text { hope for a meaningful } \\
\text { recovery }\end{array}$ & $62(54.9)$ & $88(58.3)$ & 2 & 0.58 \\
\hline $\begin{array}{l}\text { 2. To have relief of symptoms, } \\
\text { ie, pain, shortnesss of } \\
\text { breath, nausea, etc }\end{array}$ & $55(46.6)$ & $60(37.0)$ & 12 & 0.11 \\
\hline $\begin{array}{l}\text { 3. To have an adequate plan of } \\
\text { care and health services } \\
\text { available to look after you } \\
\text { at home upon discharge } \\
\text { from hospital }\end{array}$ & $46(40.0)$ & $73(44.0)$ & 6 & 0.15 \\
\hline $\begin{array}{l}\text { 4. To have trust and confidence } \\
\text { in the doctors looking after } \\
\text { you }\end{array}$ & $46(39.7)$ & $105(65.2)$ & 1 & $<0.01$ \\
\hline $\begin{array}{l}\text { 5. That you not be a physical } \\
\text { or emotional burden on } \\
\text { your family }\end{array}$ & $44(39.6)$ & $70(46.7)$ & 5 & 0.27 \\
\hline $\begin{array}{l}\text { 6. To receive respectful and } \\
\text { compassionate care from } \\
\text { health care providers }\end{array}$ & $39(33.1)$ & $59(36.6)$ & 13 & 0.53 \\
\hline $\begin{array}{l}\text { 7. To complete things and } \\
\text { prepare for life's end (life } \\
\text { review, resolving conflicts, } \\
\text { saying goodbye) }\end{array}$ & $35(30.7)$ & $76(52.8)$ & 3 & $<0.01$ \\
\hline $\begin{array}{l}\text { 8. To have an opportunity to } \\
\text { strengthen relationships } \\
\text { with people that are } \\
\text { important to you }\end{array}$ & $33(28.9)$ & $60(39.7)$ & 9 & 0.07 \\
\hline $\begin{array}{l}\text { 9. To be treated as an individual } \\
\text { with unique needs, values } \\
\text { and preferences and not } \\
\text { just a disease }\end{array}$ & 29 (25.4) & $46(28.8)$ & 20 & 0.55 \\
\hline $\begin{array}{l}\text { 10. To have information } \\
\text { regarding your medical } \\
\text { history and needs be } \\
\text { readily available to doctors } \\
\text { treating you upon } \\
\text { admission to hospital }\end{array}$ & $28(25.2)$ & $49(33.1)$ & 16 & 0.17 \\
\hline
\end{tabular}

Data presented are elements of EOL care that patients who had advanced COPD rated as extremely important. Ranking is based on the proportion of patients within the COPD cohort rating each element of EOL care as extremely important. By comparison, data from patients who had cancer according to how they rated the same elements of EOL care (in terms of importance) and our ranking of those elements are presented. The $P$ value relates to differences in proportions between patients who had COPD and patients who had cancer, in rating each element as extremely important

Patients who had COPD were most satisfied with the following elements: 'to receive adequate information about your disease including the risks and benefits of treatment options', 'to have trust and confidence in the doctors looking after you', and 'to know which doctor is the main doctor in charge of your care'. However, less than one-third of patients were completely satisfied with any of these top-ranking elements of satisfaction. 
TABLE 3

Satisfaction with current care

\begin{tabular}{|c|c|c|c|}
\hline Element & $\begin{array}{c}\operatorname{COPD}(n=118) \\
n(\%)^{*}\end{array}$ & $\begin{array}{c}\text { Cancer }(n=166), \\
n(\%)^{*}\end{array}$ & $\mathbf{P}$ \\
\hline $\begin{array}{l}\text { To receive adequate } \\
\text { information about your } \\
\text { disease including the } \\
\text { risks and benefits of } \\
\text { treatment options }\end{array}$ & $39(33.9)$ & $31(19.6)$ & 0.01 \\
\hline $\begin{array}{l}\text { To have trust and } \\
\text { confidence in the doctors } \\
\text { looking after you }\end{array}$ & $28(24.1)$ & $58(36.0)$ & 0.04 \\
\hline $\begin{array}{l}\text { To know which doctor is the } \\
\text { main doctor in charge of } \\
\text { your care }\end{array}$ & $25(21.9)$ & $58(36.0)$ & 0.01 \\
\hline $\begin{array}{l}\text { That the doctor discuss } \\
\text { concerns relating to your } \\
\text { illness and care with your } \\
\text { family present }\end{array}$ & $22(20.8)$ & $48(34.0)$ & 0.02 \\
\hline $\begin{array}{l}\text { That your illness not create } \\
\text { financial problems for your } \\
\text { family }\end{array}$ & $21(19.8)$ & $40(29.9)$ & 0.08 \\
\hline $\begin{array}{l}\text { To have trust and confidence } \\
\text { in the nurses looking after } \\
\text { you }\end{array}$ & $23(19.7)$ & $42(26.4)$ & 0.19 \\
\hline $\begin{array}{l}\text { That information about your } \\
\text { disease be communicated } \\
\text { to you by your doctor in an } \\
\text { honest manner }\end{array}$ & $22(19.6)$ & $56(36.1)$ & $<0.01$ \\
\hline $\begin{array}{l}\text { To have your spiritual or } \\
\text { religious needs met }\end{array}$ & $17(19.1)$ & $33(28.4)$ & 0.12 \\
\hline $\begin{array}{l}\text { To have an opportunity to } \\
\text { strengthen relationships } \\
\text { with people that are } \\
\text { important to you }\end{array}$ & $19(17.4)$ & $48(32.9)$ & $<0.01$ \\
\hline $\begin{array}{l}\text { To complete things and } \\
\text { prepare for life's end (life } \\
\text { review, resolving conflicts, } \\
\text { saying goodbye) }\end{array}$ & $18(16.2)$ & $46(30.2)$ & $<0.01$ \\
\hline
\end{tabular}

${ }^{*}$ Per cent is the proportion of total number of responses to a specific question. Data presented are elements of end-of-life (EOL) care that patients who had advanced chronic obstructive pulmonary disease (COPD) rated as completely satisfied. Ranking (from 1 to 10) is based on the proportion of patients within the COPD cohort rating each element of EOL care as completely satisfied. By comparison, data from patients who had cancer according to how they rated the same elements of EOL care (in terms of satisfaction) are presented. The $P$ value relates to differences in proportions between patients who had COPD and patients who had cancer, in rating each element as completely satisfied

Of the 10 top-rated items of importance in EOL care for patients who had COPD, only three appeared in the top ten ratings of satisfaction ('trust and confidence in the doctors looking after you', 'to have an opportunity to strengthen relationships' and 'to complete things and prepare for life's end'; Table 3). For nine of the 10 satisfaction elements, patients who had COPD were less satisfied with current care than cancer patients. For six of these nine elements, the proportion of COPD patients who were completely satisfied was significantly lower than the comparable proportion of cancer patients (Table 3 ).
TABLE 4

Processes of care and resource use

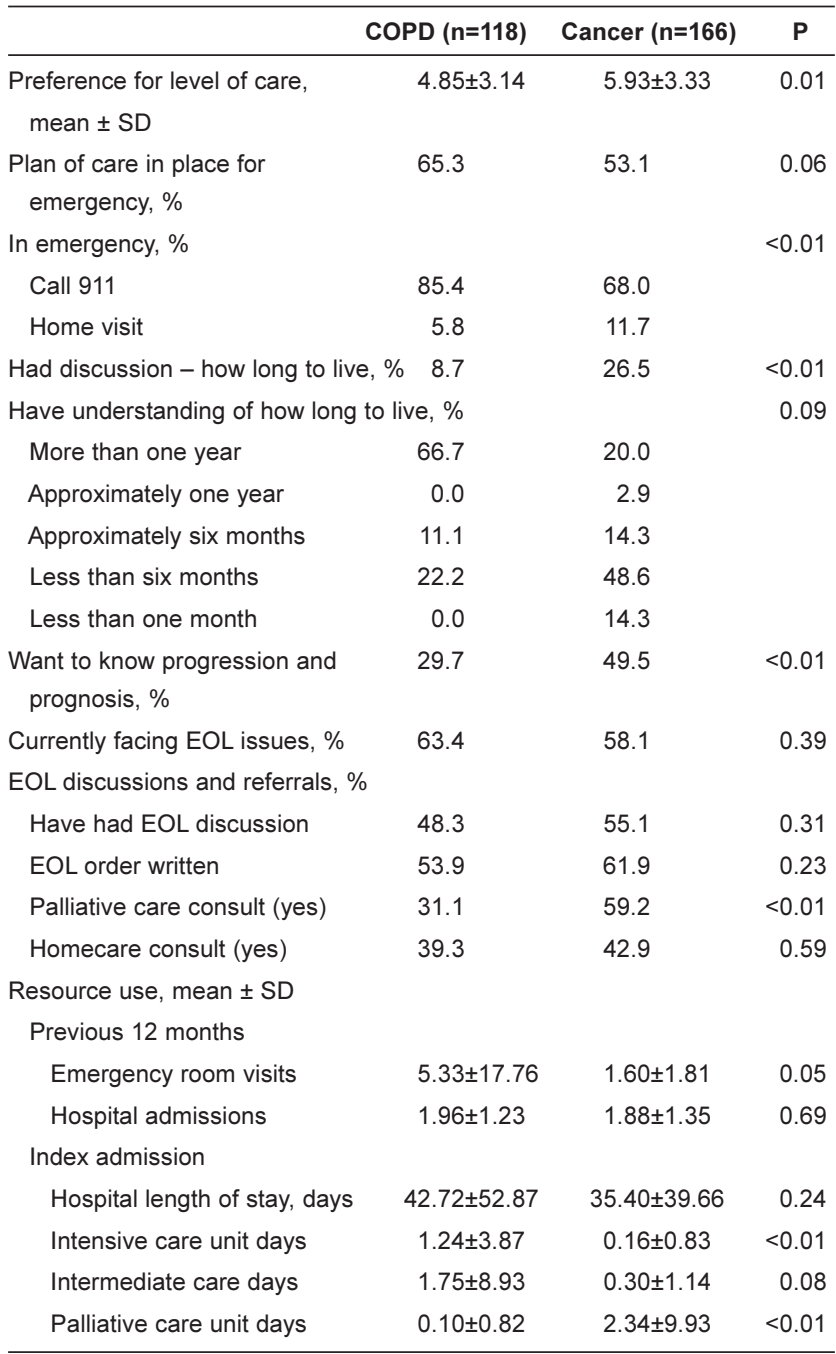

Ranking from 0 to 10 , in which 0 means extending life as much as possible and 10 means relieving discomfort as much as possible. Data on obstacles to a preferred location of death, planning for emergencies, needs for information about prognosis, discussions about end-of-life (EOL) care, and relative use of acute care services both before and during the index admission are presented. COPD Chronic obstructive pulmonary disease

Patients who had COPD or cancer had similar views on the relevance of EOL issues on models of decision making (autonomous, shared or doctor-driven) and on preferred location of death (home, hospital or does not matter; data not shown). Regarding informational needs, fewer patients who had COPD versus those who had cancer wanted to know about their prognosis and disease progression (29.7\% versus $49.5 \%$, respectively; Table 4), or about CPR, while a higher proportion of COPD patients wanted no information at all about CPR (27\% of COPD patients versus $21 \%$ of cancer patients, data not shown). Similar proportions of both patient groups (31.9\% of COPD patients, $38.5 \%$ of cancer patients) believed it was very important to know about ICUs but a lower proportion of patients who had COPD rated it extremely important to know about mechanical ventilation (29\% of COPD patients versus $45 \%$ of cancer patients). Fewer patients who had COPD, versus patients who had cancer, recalled any discussion about how long they might live (8.7\% versus $26.5 \%$, 
respectively). A higher proportion of patients who had COPD versus those who had cancer ( $85 \%$ versus $68 \%$, respectively) would call 911 as their plan in an emergency. More than $55 \%$ of patients in both groups indicated that burdens on their informal caregivers would prevent them from dying at home if that were their choice, and more than $45 \%$ in both groups indicated that a lack of adequate services would prevent a home death (data not shown). Patients who had COPD chose a level of care that was more focused on prolongation of life than patients who had cancer (Table 4).

EOL discussions occurred and EOL care orders were documented in the charts for $54 \%$ of patients who had advanced COPD and for $62 \%$ of those who had cancer. Patients who had COPD had more emergency room visits in the previous 12 months, spent more time in an ICU during the index admission and were less likely to be referred to palliative care services (Table 4). Six-month mortality was higher for patients who had cancer than for patients who had COPD (75.9\% versus $37.3 \%$, respectively).

\section{DISCUSSION}

In the present multicentre Canadian study, the elements of EOL care that were most important to patients who had COPD included the following: not to be kept alive on life support when there is little hope for a meaningful recovery, to have relief of symptoms, and to have an adequate plan of care in place beyond hospital discharge. Patients who had advanced COPD were, in general, less satisfied with their care than patients who had cancer. Imbalances in ratings of importance between elements of EOL care and satisfaction with care highlight opportunities for improvement in EOL care for patients who have COPD.

Patients who have COPD seem less inclined to discuss their prognoses. Despite the finding that 'not being kept alive on a machine when there was no meaningful chance of recovery' was an item rated as extremely important by more than $50 \%$ of both groups of patients, significantly fewer patients who had advanced COPD (versus cancer) were prepared to discuss or wanted to know about mechanical ventilation. Curtis et al $(19,20)$ have also reported that a significant proportion of patients who have advanced lung disease would decline opportunities to discuss EOL issues. In contrast, in previous studies $(21,22)$ that included COPD patients from the United States and the United Kingdom, nearly all patients believed that these issues should be discussed. These conflicting results point to a need to target our educational strategies for our COPD patients on an individual basis, something patients themselves would likely welcome based on their rating of the importance of respect for their values and preferences (Table 2).

A health care system that provides timely, comprehensive and compassionate care at the EOL will do so according to patient needs and symptom burden, and in a setting of their choice, rather than on the basis of a primary diagnosis or disease. Patients who have COPD are not strong self-advocates, and as yet, health care systems on which they increasingly depend have also failed to advocate effectively for their needs (17). It was therefore disappointing, but not surprising, that $85 \%$ of patients who had COPD would feel the need to call 911 as their plan in an emergency, perhaps reflecting less well developed or accessible home care supports, or insufficient advanced directives for this patient group. The lack of home support might explain our finding that perceived burdens on informal caregivers (for 63\% of respondents) and lack of adequate services (for $45 \%$ ) would prevent a home death if that were their preference. With recognition of inadequate palliation of dyspnea as COPD progresses, and in the context of calls from professional societies for greater involvement from palliative care services (23), we were encouraged that more than $30 \%$ of patients who had advanced COPD were referred to palliative care services during their index admission. Nevertheless, we suspect that other patients who had advanced COPD in the study might have benefited from a high quality symptom-focused interventional strategy and access to palliative care that cancer patients already received (8,24-26).

Patients who had COPD had greater use of acute care settings, including admissions to an ICU (Table 4), and fewer referral rates to palliative care, confirming previous work in the United States and the United Kingdom $(4,6,7,9)$. In our cohort of patients predicted to have a six-month mortality (approximately 50\%), fewer patients who had COPD recalled any discussion about how long they might live. Nevertheless, it is encouraging that on the wards of the participating hospitals EOL discussions occurred and EOL care orders were documented for more than $50 \%$ of all patients. What is not clear is whether such discussions in the remaining patients were attempted but declined by the patients or simply not addressed by their physicians.

Limitations of the present substudy may include our method of ranking items, which we did on the basis of the proportions of patients indicating an item as extremely important. The predominantly Caucasian sample drawn from tertiary care hospitals might limit the generalizability of our findings to other settings within Canada. We recognize that satisfaction with care does not equate to quality of care. We did not ask patients to identify which specific symptom was most important to control. Nevertheless, because dyspnea is almost universal in advanced COPD and a major contributor to poor quality of life $(13,27)$, we believe that it is reasonable to assume that symptoms include dyspnea. We did not measure prevalence of anxiety or depression, which are common occurrences in COPD $(11,28)$ that may influence patient choices and perspectives (29), or be a cause of some emergency room visits. We recognize that more qualitative studies are needed to further explore what COPD patients consider a 'meaningful recovery' after ICU admission. Furthermore, our study design did not allow us to record resource use after the index admission.

\section{CONCLUSIONS AND RECOMMENDATIONS}

For patients who had advanced COPD in our study, the most important element of EOL care was 'not to be kept alive on life support when there is little hope for a meaningful recovery'. This finding contrasts strikingly with our other findings in that such patients at high risk of six-month mortality were less likely than cancer patients to have had (or wanted) a discussion about prognosis, had rated it less important to 'complete things and prepare for life's end', were less likely to want to know about mechanical ventilation, and yet were more likely to call 911 and be admitted to an emergency room or ICU. These findings speak to our need to communicate more often and more effectively to set more realistic goals of care for patients with advanced COPD. We need to focus on strategies to improve symptom control (30) and effective care after hospital discharge. We need innovative approaches to achieve these 
aims (31) in acute care and in community settings. To set realistic goals, we need to engage patients in meaningful discussions about an uncertain prognosis, while maintaining hope about likely future events. To achieve better symptom control (30) and to optimize life remaining, we can seek help from colleagues in palliative care. We should reconsider our conventional approaches so that the management of symptoms in advanced COPD receives, at a minimum, similar attention to palliative care of key cancer-related symptoms. In addition, to minimize patient fears of being a burden to their informal caregivers, as well as to reduce emergency room visits and hospital admissions, we should be developing adequate communitybased resources on which patients and informal caregivers living with COPD or any advanced disease can depend on (32), even in a crisis (33).

ACKNOWLEDGEMENTS: The authors would like to thank Diane Allan, Research Associate at the Centre on Aging, University of Victoria, Victoria, British Columbia, for her assistance with data analysis.

We would also like to thank all the study personnel and site investigators (see reference 16 for full details) who participated in this study at the participating hospitals: Queen Elizabeth II Health Sciences Centre, Halifax, Nova Scotia ( 800 beds); Kingston General Hospital, Kingston, Ontario (400 beds); Toronto General Hospital, Toronto, Ontario (471 beds); St Paul's Hospital, Vancouver, British Columbia (400 beds); Royal Alexandra Hospital, Edmonton, Alberta (520 beds).

FUNDING: This study was supported by the National Health Research and Development Program of Canada.

\section{REFERENCES}

1. Lacasse Y, Brooks D, Goldstein RS. Trends in the epidemiology of COPD in Canada, 1980 to 1995. COPD and Rehabilitation Committee of the Canadian Thoracic Society. Chest 1999;116:306-13.

2. Respiratory Disease in Canada. Ottawa: Canadian Institute for Health Information, Canadian Lung Association, Health Canada, Statistics Canada, 2001. <http://www.phac-aspc.gc.ca/publicat/rdcmrc01/index.html > (Version current at June 2, 2008).

3. Jemal A, Ward E, Hao Y, Thun M. Trends in the leading causes of death in the United States, 1970-2002. JAMA 2005;294:1255-9.

4. Lynn J, Ely EW, Zhong Z, et al. Living and dying with chronic obstructive pulmonary disease. J Am Geriatr Soc 2000;48(5 Suppl):S91-100.

5. Patil SP, Krishnan JA, Lechtzin N, Diette GB. In-hospital mortality following acute exacerbations of chronic obstructive pulmonary disease. Arch Intern Med 2003;163:1180-6.

6. Au DH, Udris EM, Fihn SD, McDonell MB, Curtis JR. Differences in health care utilization at the end of life among patients with chronic obstructive pulmonary disease and patients with lung cancer. Arch Intern Med 2006;166:326-31.

7. Gore JM, Brophy CJ, Greenstone MA. How well do we care for patients with end stage chronic obstructive pulmonary disease (COPD)? A comparison of palliative care and quality of life in COPD and lung cancer. Thorax 2000;55:1000-6.

8. Solano JP, Gomes B, Higginson IJ. A comparison of symptom prevalence in far advanced cancer, AIDS, heart disease, chronic obstructive pulmonary disease and renal disease. J Pain Symptom Manage 2006;31:58-69.

9. Claessens MT, Lynn J, Zhong Z, et al. Dying with lung cancer or chronic obstructive pulmonary disease: Insights from SUPPORT. Study to Understand Prognoses and Preferences for Outcomes and Risks of Treatments. J Am Geriatr Soc 2000;48(5 Suppl):S146-53.
10. Edmonds P, Karlsen S, Khan S, Addington-Hall J. A comparison of the palliative care needs of patients dying from chronic respiratory diseases and lung cancer. Palliat Med 2001;15:287-95.

11. Bailey PH. The dyspnea-anxiety-dyspnea cycle - COPD patients' stories of breathlessness: "It's scary /when you can't breathe". Qual Health Res 2004;14:760-78.

12. Jones I, Kirby A, Ormiston P, et al. The needs of patients dying of chronic obstructive pulmonary disease in the community. Fam Pract 2004;21:310-3.

13. Elkington H, White P, Addington-Hall J, Higgs R, Edmonds P. The healthcare needs of chronic obstructive pulmonary disease patients in the last year of life. Palliat Med 2005;19:485-91.

14. Elkington $\mathrm{H}$, White P, Addington-Hall J, Higgs R, Pettinari C. The last year of life of COPD: A qualitative study of symptoms and services. Respir Med 2004;98:439-45.

15. Heyland DK, Dodek P, Rocker G, et al. What matters most in endof-life care: Perceptions of seriously ill patients and their family members. CMAJ 2006;174:627-33.

16. Heyland DK, Groll D, Rocker G, et al. End-of-life care in acute care hospitals in Canada: A quality finish? J Palliat Care 2005;21:142-50.

17. Partridge MR. Patients with COPD: Do we fail them from beginning to end? Thorax 2003;58:373-5.

18. Liao S, Arnold RM. Chronic obstructive pulmonary disease: Thinking outside the opioid box. J Palliat Med 2007;10:781-2.

19. Curtis JR, Engelberg RA, Wenrich MD, Au DH. Communication about palliative care for patients with chronic obstructive pulmonary disease. J Palliat Care 2005;21:157-64.

20. Curtis JR, Engelberg RA, Nielsen EL, Au DH, Patrick DL. Patientphysician communication about end-of-life care for patients with severe COPD. Eur Respir J 2004;24:200-5.

21. Gaber KA, Barnett M, Planchant Y, McGavin CR. Attitudes of 100 patients with chronic obstructive pulmonary disease to artificial ventilation and cardiopulmonary resuscitation. Palliat Med 2004;18:626-9

22. Heffner JE, Fahy B, Hilling L, Barbieri C. Attitudes regarding advance directives among patients in pulmonary rehabilitation. Am J Respir Crit Care Med 1996;154:1735-40.

23. O'Donnell DE, Aaron S, Bourbeau J, et al. Canadian Thoracic Society recommendations for management of chronic obstructive pulmonary disease - 2003. Can Respir J 2003;10(Suppl A):11A-65A.

24. Kite S, Jones K, Tookman A. Specialist palliative care and patients with noncancer diagnoses: The experience of a service. Palliat Med 1999; 13:477-84.

25. Luddington L, Cox S, Higginson I, Livesley B. The need for palliative care for patients with non-cancer diseases: A review of the evidence. Int J Palliat Nurs 2001;7:221-6.

26. Grbich C, Maddocks I, Parker D, et al. Identification of patients with noncancer diseases for palliative care services. Palliat Support Care 2005;3:5-14.

27. Skilbeck J, Mott L, Page H, Smith D, Hjelmeland-Ahmedzai S, Clark D. Palliative care in chronic obstructive airways disease: A needs assessment. Palliat Med 1998;12:245-54.

28. Gudmundsson G, Gislason T, Janson C, et al. Depression, anxiety and health status after hospitalisation for COPD: A multicentre study in the Nordic countries. Respir Med 2006;100:87-93.

29. Stapleton RD, Nielsen EL, Engelberg RA, Patrick DL, Curtis JR. Association of depression and life-sustaining treatment preferences in patients with COPD. Chest 2005;127:328-34.

30. Rocker GM, Sinuff T, Horton R, Hernandez P. Advanced chronic obstructive pulmonary disease: Innovative approaches to palliation. J Palliat Med 2007;10:783-97.

31. Booth S, Farquhar M, Gysels M, Bausewein C, Higginson IJ. The impact of a breathlessness intervention service (BIS) on the lives of patients with intractable dyspnea: A qualitative phase 1 study. Palliat Support Care 2006;4:287-93.

32. Intermediate care - Hospital-at-Home in chronic obstructive pulmonary disease: British Thoracic Society guideline. Thorax 2007;62:200-10.

33. Rocker G. Defining moments: End-of-life care in the back of a truck. CMAJ 2007;176:1614-5. 


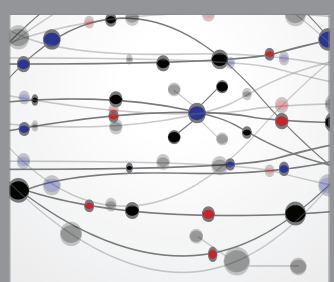

The Scientific World Journal
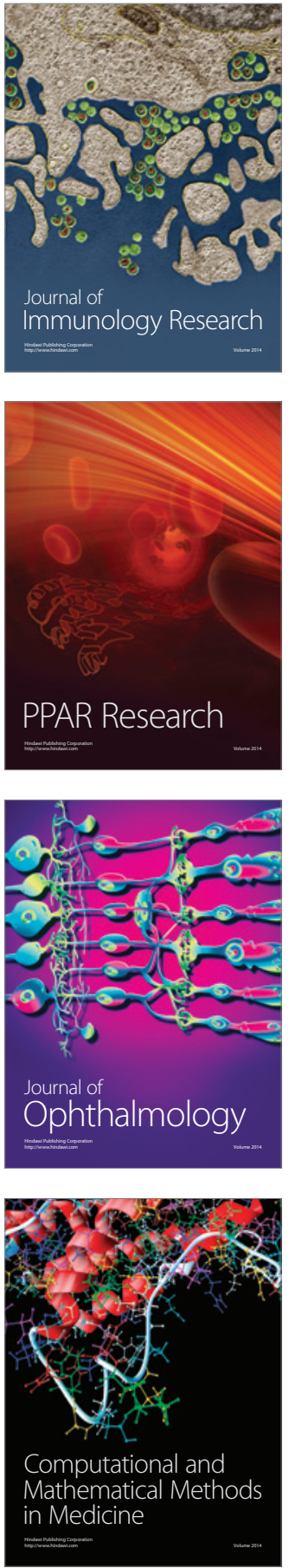

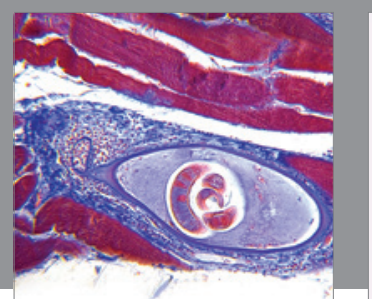

Gastroenterology Research and Practice

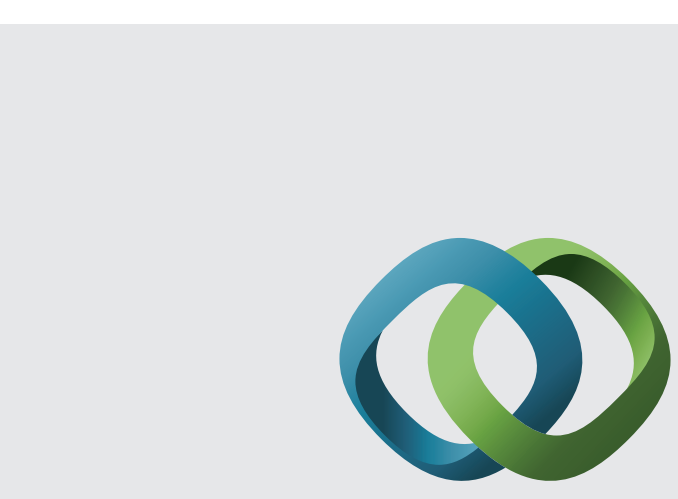

\section{Hindawi}

Submit your manuscripts at

http://www.hindawi.com
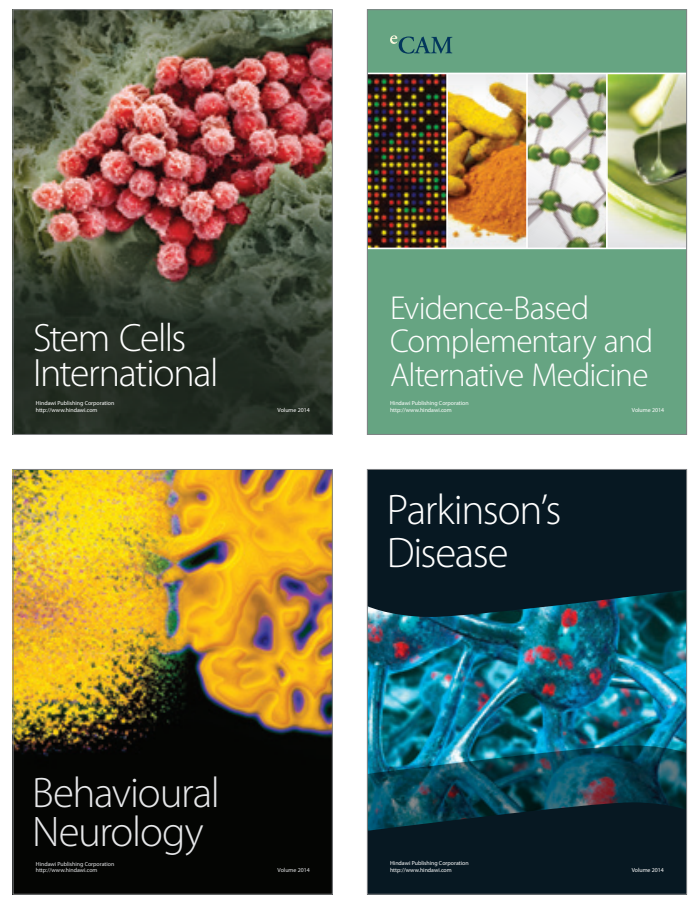
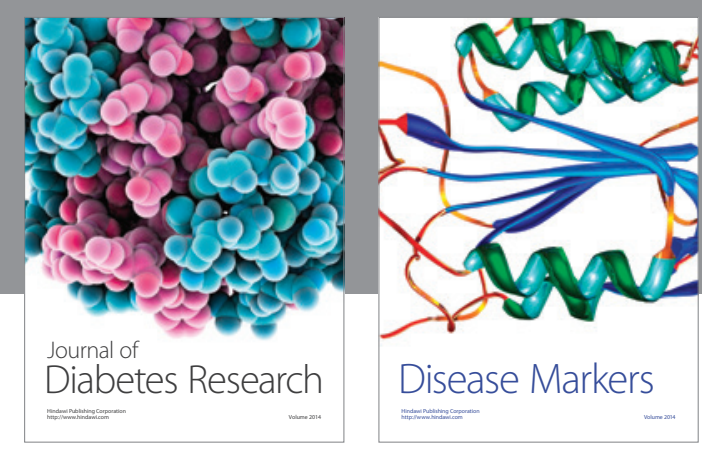

Disease Markers
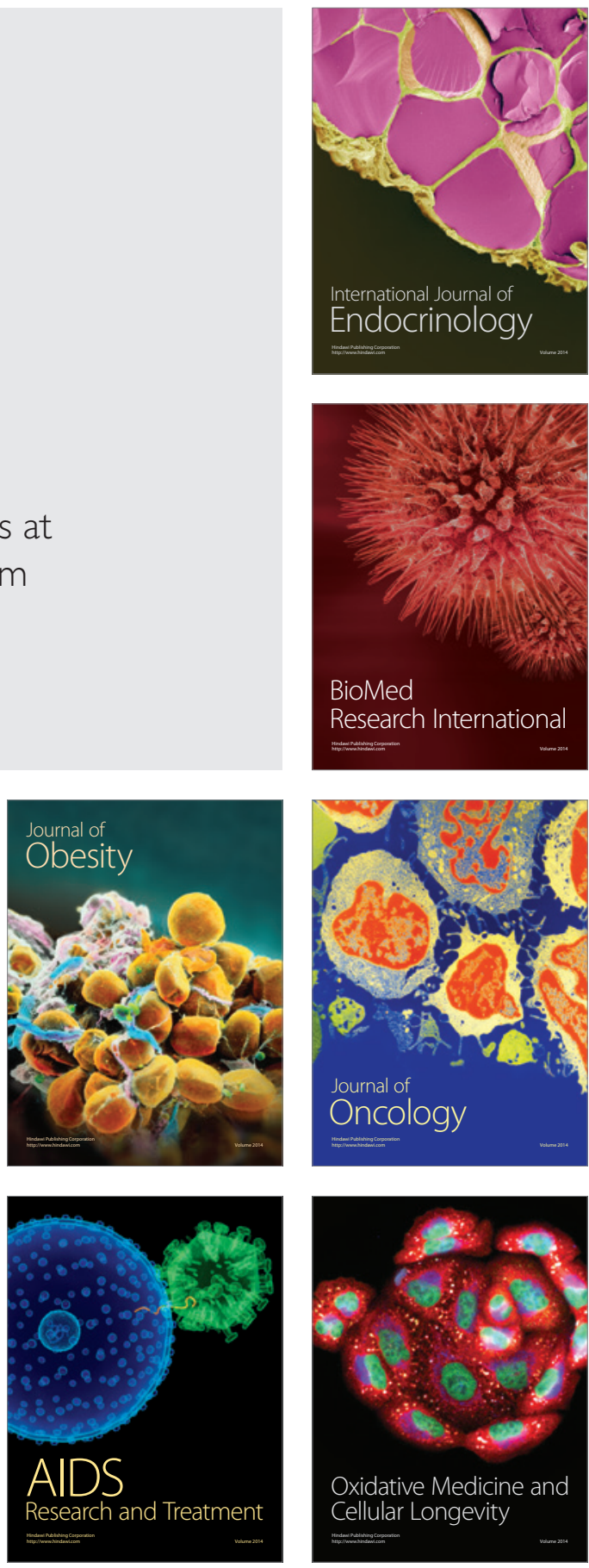